\title{
Comparison of As (III) Adsorption Capacity in Aqueous Solution with Iron Nano Oxide and Nano Absorber BACI-2017
}

\author{
Hossein Ghafourian, Mohammad Rabbani, Zahra Ghazanfari \\ Department of Environmental Engineering, Islamic Azad University, North Branch Tehran, Iran \\ Email address: \\ h_ghafourian@iau-tnb.ac.ir (H. Ghafourian)
}

\section{To cite this article:}

Hossein Ghafourian, Mohammad Rabbani, Zahra Ghazanfari. Comparison of As (III) Adsorption Capacity in Aqueous Solution with Iron Nano Oxide and Nano Absorber BACI-2017. International Journal of Computational and Theoretical Chemistry.

Vol. 6, No. 1, 2018, pp. 21-27. doi: 10.11648/j.ijctc.20180601.13

Received: December 19, 2017; Accepted: January 2, 2018; Published: January 26, 2018

\begin{abstract}
Arsenic, one of the elements having most terrible impact on the human being, is threatening the world continuously. It exists in the combined form in rocks under earth which on dissolution contaminates ground water. By various mean, such as industrial activities, it can enter into vital ecological cycle and cause hazards to human health. In the previous paper, it is shown that use of activated carbons such as BACI-2017 can assist in removing As (III) at highest level of $455 \mathrm{mg} / \mathrm{g}$ from contaminated water. In this study, the removal of arsenic (III) is compared when different level of nano iron oxides are present. In order to determine the optimal extraction of As (III) in presence of nano iron oxide solutions containing different arsenic concentrations, 5 to $400 \mathrm{mg} / \mathrm{l}$ with nano iron particles of 0.5 to $0.1 \mathrm{~g}$ have been used. BACI-2017 with particle sizes, mesh $4 \times 8$ and 100 or higher been also employed. The separation of As (III) was carried out using 0.1 gram of BACI-2017. The maximum As (III) extraction in presence of nano iron oxide and combined nano iron oxide with BACI-2017 are shown to be $19.47 \mathrm{mg} / \mathrm{g}$ and $99.36 \mathrm{mg} / \mathrm{g}$ respectively during 15 minutes contact times.
\end{abstract}

Keywords: Nanotechnology, Separation, As (III), Iron Nano Oxide, BACI-2017

\section{Introduction}

Arsenic exists in the combined form in rocks under earth. Arsenic after dissolution contaminates ground water [1, 2, 3]. Arsenic is naturally pseudo-metal, which is very fluid in the environment. Its movement largely depends on the mineral's origin, the state of oxidation and its mobility mechanisms. According to the oxidation state, arsenic can exist in four forms, which include arsenite, arsenate, arsenic and arsine. Among these four arsenic species, the most common form, usually found in water, is arsenite and arsenate [4] The concentration of arsenic in natural fresh water sources varies from 0.3 to $3.0 \mu \mathrm{g} / \mathrm{L}$. Generally, high concentrations of arsenic are found mostly in groundwater and usually in the form of As (III) [5]. About 200 million people worldwide are exposed to a concentration of arsenic in drinking water above the limit of 10 $\mu \mathrm{g} / \mathrm{L}$. The amount set by the World Health Organization (WHO) [6]. The purpose of this research is to determine and compare adsorption capacity of As (III) in presence of nano iron oxide and BACI-2017. BAC-2017 is available in different particle size, mesh 4x8 and mesh 100 and higher [7-10].

\section{Experiments}

All chemicals used were of analytical grades and were obtained from Merck Chemicals. All the solutions were prepared in distilled water. Stock solution of As (III) was prepared by dissolving $1.73 \mathrm{~g}$ sodium arsenic oxide $(\mathrm{AsNaO} 2)$ in 1 liter of distilled water which resulted in 1.00 $\mathrm{ml}$ of solution containing $1.00 \mathrm{mg}$ of CAs (III). Other standard As (III) solutions were prepared by diluting the stock solution proportionally. The experimental tests were carried out in presence of iron nano oxide of 0.5 and 0.1 gram and adsorbent BACI-2017 supplied by Beshel Activated Carbon. $50 \mathrm{ml}$ of arsenic (III) solution arsenic (III) solution with different concentrations of 100, 200, 300, 400, $500,1000 \mathrm{mg} / 1$ in $100 \mathrm{ml}$ Erlenmeyer glass with stopper. The mixture was shaken for one minute vigorously by hand and 
then after 15 minutes retention time arsenic solution was filtrate. In all experiments the $\mathrm{pH}$ was about 8.5 and contact time was 15 minutes. After the time passed, samples were taken in sample containers, until this stage of work at the Faculty of Chemistry of Islamic Azad University-Tehran North Branch. After filtration with 0.45 micron of Whatman marking paper, the samples were measured by hydride atomic absorption device Model: SpectrAA-400 + Varian (VGA.76). The experiments were done at $25^{\circ} \mathrm{C}$. The data analysis was performed using by Excel software. Furthermore the results were interrogated by the Freundlich and Langmuir procedures.

The percentage of arsenic extracted was calculated using the following formula 1 :

$$
\text { Removal Percentage }=\left[\left(\mathrm{C}_{\mathrm{o}}-\mathrm{C}_{\mathrm{e}}\right) / \mathrm{C}_{\mathrm{o}}\right] * 100
$$

$\mathrm{C}_{\mathrm{o}}$ : As (III) initial concentration $(\mathrm{mg} / \mathrm{g})$

$\mathrm{C}_{\mathrm{e}}$ : As (III) Equilibrium concentration $(\mathrm{mg} / \mathrm{g})$

\section{Results and Discussion}

\subsection{Removal Amount}

The experiment was done with $50 \mathrm{ml}$ of As (III) solutions at six different concentrations in presence of $0.5 \mathrm{~g}$ of iron nano oxide. The percentage of As (III) removal for each solution is shown in Table 1. The average percentage of arsenic (III) removed is about $99.8 \%$, see Table 1 .

Table 1. Determination the optimal amount of As (III) extracted in presence of $0.5 \mathrm{~g}$ of iron nano oxide.

\begin{tabular}{llllll}
\hline Sample & $\mathbf{C}_{\mathbf{0}}(\mathbf{m g} / \mathbf{l})$ & iron nano oxide $(\mathbf{g})$ & Time Contact (Minute) & $\mathbf{C}_{\mathbf{e}}$ (mg/l) & \% Removal of As (III) \\
\hline 1 & 5 & 0.5 & 15 & 0.005 \\
2 & 10 & 0.5 & 15 & 0.010 \\
3 & 20 & 0.5 & 15 & 0.031 & 99.90 \\
4 & 30 & 0.5 & 15 & 0.073 & 99.90 \\
5 & 50 & 0.5 & 15 & 0.198 & 99.85 \\
6 & 100 & 0.5 & 15 & 0.483 & 99.60 \\
\hline
\end{tabular}

Similarly, Table 2 shows the percentage of As (III) removed from solution containing seven different concentrations of arsenic in presence of $0.1 \mathrm{~g}$ iron nano oxide. The average percentage removed is around $98.6 \%$ in this case.

Table 2. The amount As (III) extracted from arsenic solutions in presence $0.1 \mathrm{~g}$ of iron nano oxide.

\begin{tabular}{llllll}
\hline Sample & $\mathbf{C}_{\mathbf{0}}(\mathbf{m g} / \mathbf{l})$ & iron nano oxide $(\mathbf{g})$ & Time Contact (Minute) & $\mathbf{C}_{\mathrm{e}}(\mathbf{m g} / \mathbf{l})$ & \% Removal of As (III) \\
\hline 1 & 10 & 0.1 & 15 & 0.435 \\
2 & 30 & 0.1 & 15 & 0.662 \\
3 & 50 & 0.1 & 15 & 0.722 & 95.65 \\
4 & 100 & 0.1 & 15 & 0.830 & 97.79 \\
5 & 200 & 0.1 & 15 & 0.900 & 98.56 \\
6 & 300 & 0.1 & 15 & 0.958 & 99.17 \\
7 & 400 & 0.1 & 15 & 1.060 & 99.68 \\
\hline
\end{tabular}

When BACI-2017 (with mesh size of 4x8 particles), is used the extraction of As (III) from seven different solutions in presence of $0.1 \mathrm{~g}$ of nano iron oxide is reduced compared with those in Table 3 . The average percentage extraction of Arsenic is this case is about $96.2 \%$

Table 3. Removal of As (III) from different arsenic solutions in presence of 0.1g of nano iron oxide particles and BACI-2017.

\begin{tabular}{|c|c|c|c|c|c|}
\hline Sample & $\mathrm{C}_{0}(\mathrm{mg} / \mathrm{l})$ & iron nano oxide \& BACI-2017 (g) & Time Contact (Minute) & $\mathrm{C}_{\mathrm{e}}(\mathrm{mg} / \mathrm{l})$ & \% Removal of As (III) \\
\hline 1 & 5 & 0.1 & 15 & 0.572 & 88.56 \\
\hline 2 & 10 & 0.1 & 15 & 0.616 & 93.84 \\
\hline 3 & 20 & 0.1 & 15 & 0.666 & 96.67 \\
\hline 4 & 30 & 0.1 & 15 & 0.716 & 97.61 \\
\hline 5 & 50 & 0.1 & 15 & 0.775 & 98.45 \\
\hline 6 & 100 & 0.1 & 15 & 0.890 & 99.11 \\
\hline 7 & 200 & 0.1 & 15 & 1.290 & 99.36 \\
\hline
\end{tabular}

When BAC1-2017 with mesh size of 100 or higher is used, the results show with increasing concentration of arsenic in the solutions, its extraction capacity is decreased, see Table 4.

Table 4. Extraction of As (III) in presence of 0.1g BACI-2017 (with 100 and higher than 100 mesh sizes).

\begin{tabular}{|c|c|c|c|c|c|}
\hline Sample & $\mathrm{C}_{0}(\mathrm{mg} / \mathrm{l})$ & BACI-2017 (g) & Time Contact (Minute) & $\mathrm{C}_{\mathrm{e}}(\mathrm{mg} / \mathrm{l})$ & \% Removal of As (III) \\
\hline 1 & 100 & 0.1 & 15 & 1 & 99 \\
\hline 2 & 200 & 0.1 & 15 & 4 & 98 \\
\hline 3 & 300 & 0.1 & 15 & 9 & 97 \\
\hline 4 & 400 & 0.1 & 15 & 20 & 95 \\
\hline 5 & 500 & 0.1 & 15 & 40 & 92 \\
\hline 6 & 1000 & 0.1 & 15 & 90 & 91 \\
\hline
\end{tabular}




\subsection{Review of Langmuir Adsorption Isotherms}

In addition to the extraction results shown above, the percentage removal of As (III) was investigated using Langmuir and Freundlich isotherms (5).

\subsubsection{Langmuir Absorbed Isotherm}

Homogeneous layer absorption is fundamental in Langmuir's theory. It also assume that absorption of material is confined to an area where there is no other absorption occurring in that area. The rate of absorption is proportional to desorption, surface area and time (5).

The results of As (III) extractions were plotted on the Langmuir graph where $1 / \mathrm{Ce}$ is plotted against $1 /$ qe. Where qe is obtained from the following formula 2 :

$$
\mathrm{qe}=\left[\left(\mathrm{C}_{\mathrm{o}}-\mathrm{C}_{\mathrm{e}}\right) / \mathrm{m}\right]^{*} \mathrm{v}
$$

qe: Equilibrium uptake ( $\mathrm{mg} / \mathrm{g})$

$\mathrm{v}$ : Volume of solution (L)

$\mathrm{C} 0$ : As (III) initial concentration $(\mathrm{mg} / \mathrm{g})$

Ce: As (III) Equilibrium concentration ( $\mathrm{mg} / \mathrm{g}$ )

$\mathrm{m}$ : Mass of adsorbent material ( $\mathrm{g}$ )

The maximum amount of As (III) adsorption inform the results in Table 5 calculated according to the Langmuir adsorption isotherm is $4.95 \mathrm{mg} / \mathrm{g}$ [see Table 5 and Figure 1].

Table 5. Data for Langmuir isotherm for the case when $0.5 \mathrm{~g}$ of nano iron oxide is used (see Table 1).

\begin{tabular}{|c|c|c|c|c|}
\hline No. & qe (mg/g) & $\mathrm{C}_{\mathrm{e}}(\mathrm{mg} / \mathrm{l})$ & $1 / q_{\mathrm{e}}$ & $1 / C_{e}$ \\
\hline 1 & 0.25 & 0.005 & 4.01 & 200 \\
\hline 2 & 0.50 & 0.010 & 2.00 & 100 \\
\hline 3 & 1.00 & 0.031 & 1.00 & 32.26 \\
\hline 4 & 1.49 & 0.073 & 0.67 & 13.7 \\
\hline 5 & 2.48 & 0.198 & 0.40 & 5.05 \\
\hline 6 & 4.95 & 0.483 & 0.20 & 2.07 \\
\hline
\end{tabular}

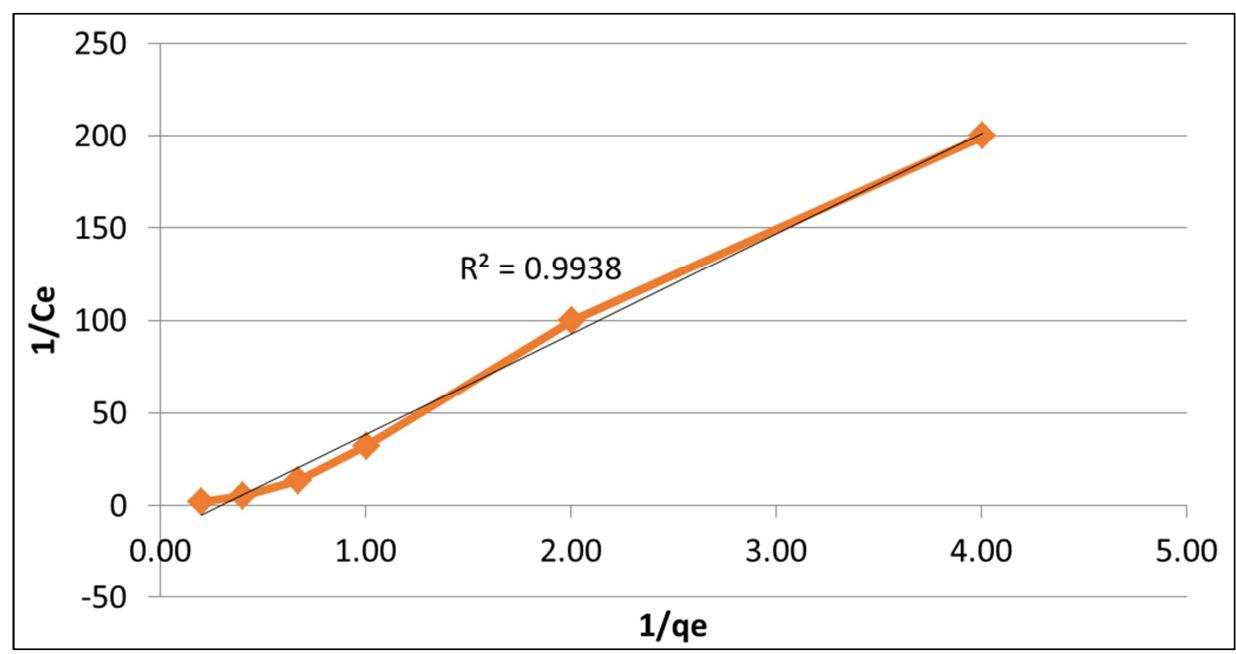

Figure 1. Langmuir adsorption isotherm for As (III) removal when $0.5 \mathrm{~g}$ of nano iron oxide is used.

Similarly, the maximum amount of As (III) adsorption capacity in experiment where $0.1 \mathrm{~g}$ of nano iron oxide is used calculated by Langmuir adsorption isotherm to be $19.47 \mathrm{mg} / \mathrm{g}$ [see Table 6 and Figure 2].

Table 6. Data to determine Langmuir isotherm for where $0.1 \mathrm{~g}$ of nano iron oxide is present (see Table 2).

\begin{tabular}{lllll}
\hline No. & qe $(\mathbf{m g} / \mathbf{g})$ & $\mathbf{C}_{\mathrm{e}}(\mathbf{m g} / \mathbf{l})$ & $\mathbf{1} / \mathbf{q}_{\mathrm{e}}$ & $\mathbf{1}$ \\
\hline 1 & 0.28 & 0.435 & 3.54 & 0.86 \\
2 & 1.17 & 0.662 & 0.47 & 1.31 \\
3 & 2.14 & 0.722 & 0.22 & 1.45 \\
4 & 4.59 & 0.830 & 0.10 & 0.98 \\
5 & 9.55 & 0.900 & 0.07 & 3.82 \\
7 & 14.52 & 0.958 & 0.05 \\
\hline
\end{tabular}




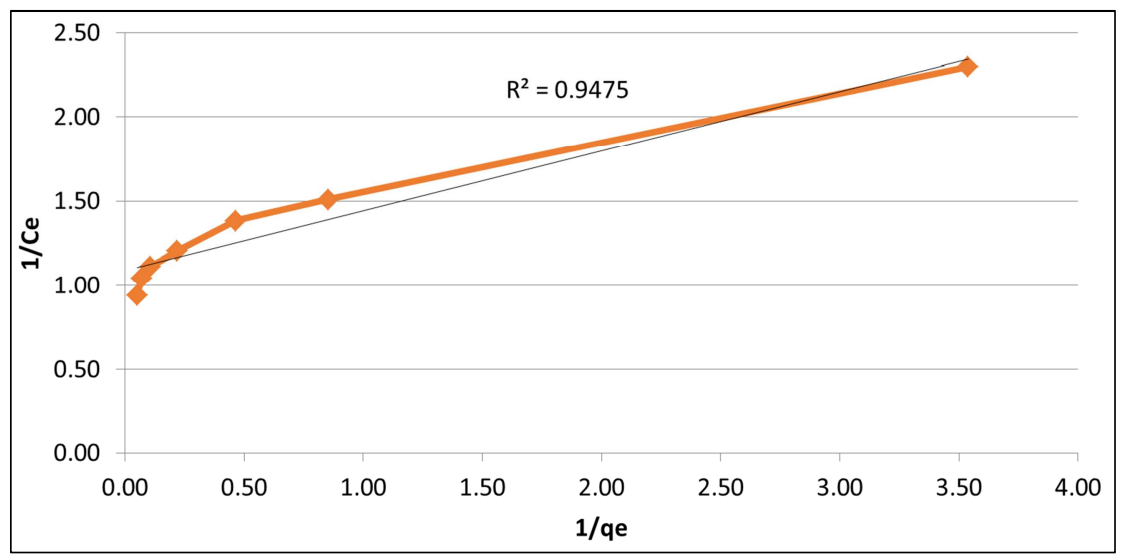

Figure 2. Langmuir adsorption isotherm study for extraction of As (III) when $0.1 \mathrm{~g}$ of nano iron oxide was used.

The maximum As (III) extractable calculated by Langmuir adsorption isotherm was $99.36 \mathrm{mg} / \mathrm{g}$ [Table 7 and Figure 3]. When $0.1 \mathrm{~g}$ of nano iron oxide and BACI-2017 with mesh size of $4 \times 8$ are used.

Table 7. Data to determine Langmuir isotherm for extraction of As (III) when both $0.1 \mathrm{~g}$ nano iron nano oxide and BAKI-2017 with mesh size (4x8) are present.

\begin{tabular}{lllll}
\hline No. & $\mathbf{q e}(\mathbf{m g} / \mathbf{g})$ & $\mathbf{C}_{\mathrm{e}}(\mathbf{m g} / \mathbf{l})$ & $\mathbf{1 / \mathbf { q } _ { \mathrm { e } }}$ \\
\hline 1 & 2.21 & 0.572 & 0.45 & $\mathbf{1 / \mathbf { C } _ { \mathrm { e } }}$ \\
2 & 4.69 & 0.616 & 0.21 & 1.75 \\
3 & 9.67 & 0.666 & 0.10 & 1.62 \\
4 & 14.64 & 0.716 & 0.07 & 1.50 \\
5 & 24.61 & 0.775 & 0.04 & 1.40 \\
6 & 49.56 & 0.890 & 0.02 & 1.29 \\
7 & 99.36 & 1.290 & 0.01 & 0.78 \\
\hline
\end{tabular}

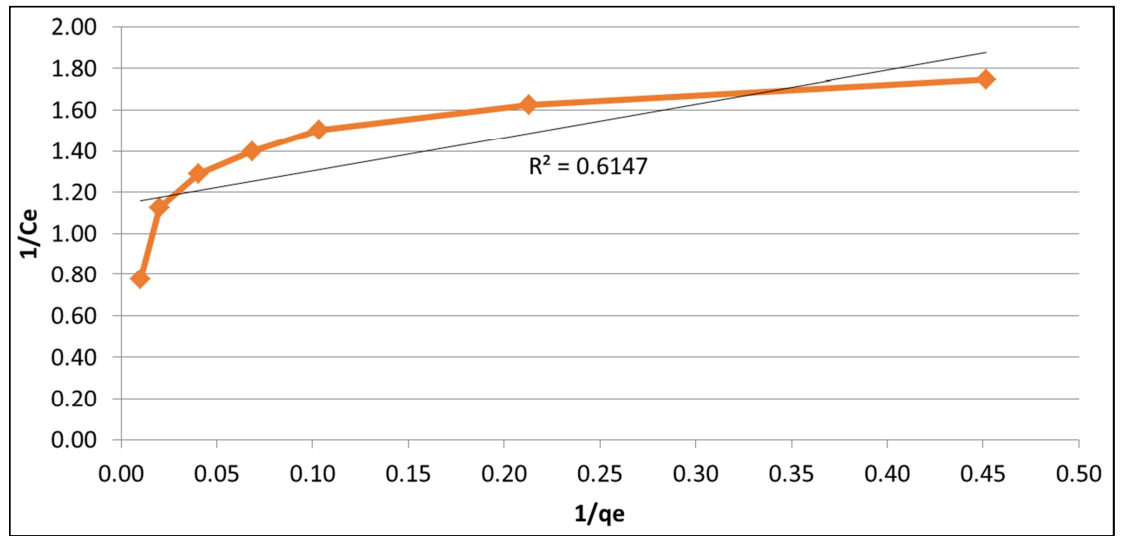

Figure 3. Langmuir adsorption isotherm for extraction of As (III) when both nano oxide (0.1g) and BAKI- 2017 with mesh size (4x8) are used.

\subsubsection{Freundlich Absorption Isotherm}

In this model, contrary to the Langmuir model, multilayers adsorption is allowed. The Freundlich model responds to low concentrations of metals in solutions, but not so well at high concentrations. This model shows higher absorption than the actual experimental values. It is assume the mode of biological adsorbents to be heterogeneous in terms of their energy levels. Therefore, at low concentrations the model's prediction is proportional to the experimental values, but at higher concentrations after the absorption layer the metal ion tendency to re-adsorb on the pre-adsorbed layer decreases surface. In this case the predicted values differ from those which are measured (8). The results of the samples are plotted on the Freundlich diagram based on LnCe and Lnqe. qe is obtained from the equation 1. The maximum As (III) adsorption from solutions when $0.5 \mathrm{~g}$ nano iron oxide is present calculated by Freundlich adsorption isotherm is 4.95 $\mathrm{mg} / \mathrm{g}$ [Table 8 and Figure 4], which is the same as that predicted by the Langmuir method.

Table 8. Data to determine Freundlich isotherm for $0.5 \mathrm{~g}$ iron nano oxide.

\begin{tabular}{lllll}
\hline No. & qe (mg/g) & $\mathbf{C}_{\mathbf{e}}(\mathbf{m g} / \mathbf{L})$ & $\mathbf{L n q}_{\mathbf{e}}$ & $\mathbf{L n C}_{\mathbf{e}}$ \\
\hline 1 & 0.25 & 0.005 & -1.39 & -5.30 \\
2 & 0.50 & 0.010 & -0.70 & -4.61 \\
3 & 1.00 & 0.031 & 0.00 & -3.47 \\
4 & 1.49 & 0.073 & 0.40 & -2.62 \\
5 & 2.48 & 0.198 & 0.91 & -1.62 \\
6 & 4.95 & 0.483 & 1.60 & -0.73 \\
\hline
\end{tabular}




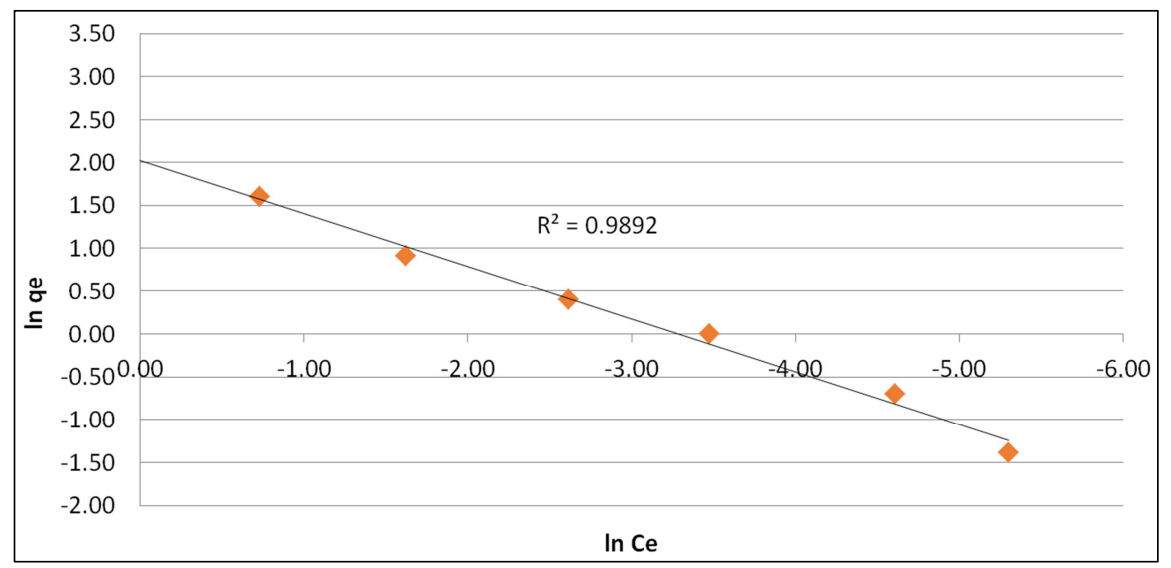

Figure 4. Freundlich adsorption isotherm for extraction of As (III) when $0.5 \mathrm{~g}$ of nano iron oxide is used.

The maximum As (III) adsorption capacity when $0.1 \mathrm{~g}$ of nano iron oxide is present calculated by the Freundlich adsorption isotherm is $19.47 \mathrm{mg} / \mathrm{g}$ [Table 9 and Figure 5], which is incidentally the same as those predicted by the Langmuir method.

Table 9. Data to determine Freundlich isotherm for when nano iron oxide $(0.1 \mathrm{~g})$ is used.

\begin{tabular}{lllll}
\hline No. & qe (mg/g) & $\mathbf{C}_{\mathrm{e}}(\mathbf{m g} / \mathbf{L})$ & $\mathbf{L n q}_{\mathrm{e}}$ & $\mathbf{L n C}_{\mathrm{e}}$ \\
\hline 1 & 0.28 & 0.435 & -1.26 & -0.83 \\
2 & 1.17 & 0.662 & 0.16 & -0.41 \\
3 & 2.14 & 0.722 & 0.76 & -0.33 \\
4 & 4.59 & 0.83 & 1.52 & -0.19 \\
5 & 9.55 & 0.9 & 2.26 & -0.11 \\
6 & 14.52 & 0.958 & 2.68 & -0.04 \\
7 & 19.47 & 1.06 & 2.97 & 0.06 \\
\hline
\end{tabular}

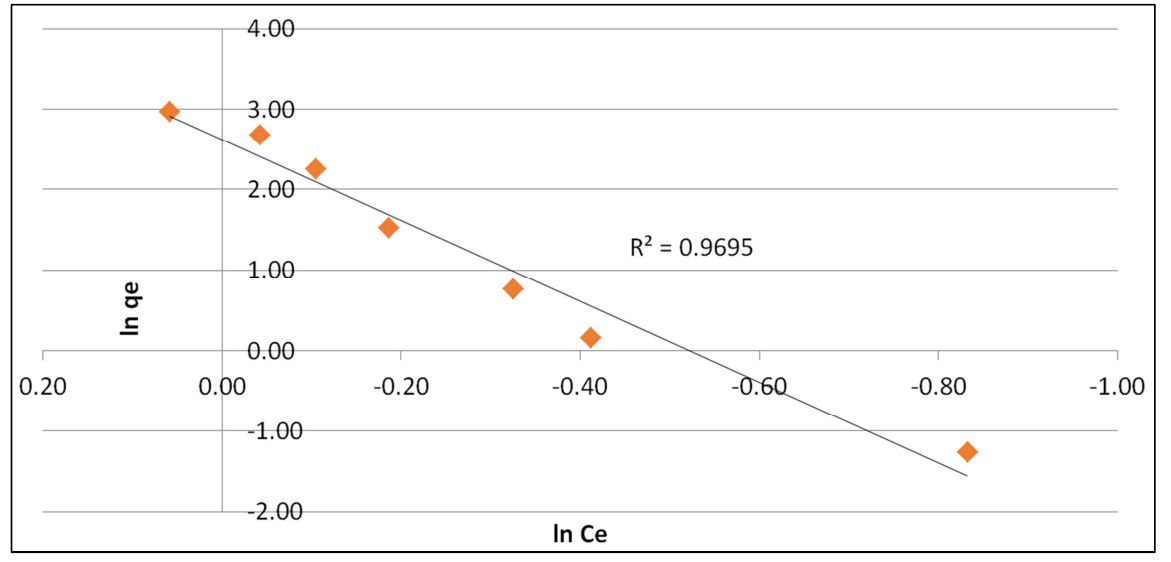

Figure 5. Freundlich adsorption isotherm for extraction of As (III) when nano iron oxide is $0.1 \mathrm{~g}$.

The maximum As (III) adsorption capacity for the batch experiment where 01.g nano iron oxide and BACI-2017 (with mesh size of $4 \times 8$ ) are present calculated by Freundlich adsorption isotherm is $99.36 \mathrm{mg} / \mathrm{g}$ [Table 10 and Figure 6]. Again this value is the same as that obtained by the Langmuir method.

Table 10. Results to determine Freundlich isotherm when both $0.1 \mathrm{~g}$ of nano iron nano oxide and BACI-2017 with mesh size (4x8) are used.

\begin{tabular}{lllll}
\hline No. & $\mathbf{q e}(\mathbf{m g} / \mathbf{g})$ & $\mathbf{C}_{\mathbf{e}}(\mathbf{m g} / \mathbf{L})$ & $\mathbf{L n q}_{\mathbf{e}}$ & $\mathbf{L n C}_{\mathbf{e}}$ \\
\hline 1 & 2.21 & 0.572 & 0.79 & -0.56 \\
2 & 4.69 & 0.616 & 1.55 & -0.48 \\
3 & 9.67 & 0.666 & 2.27 & -0.41 \\
4 & 14.64 & 0.716 & 2.68 & -0.33 \\
5 & 24.61 & 0.775 & 3.20 & -0.25 \\
6 & 49.56 & 0.890 & 3.90 & -0.12 \\
7 & 99.36 & 1.290 & 4.60 & 0.25 \\
\hline
\end{tabular}




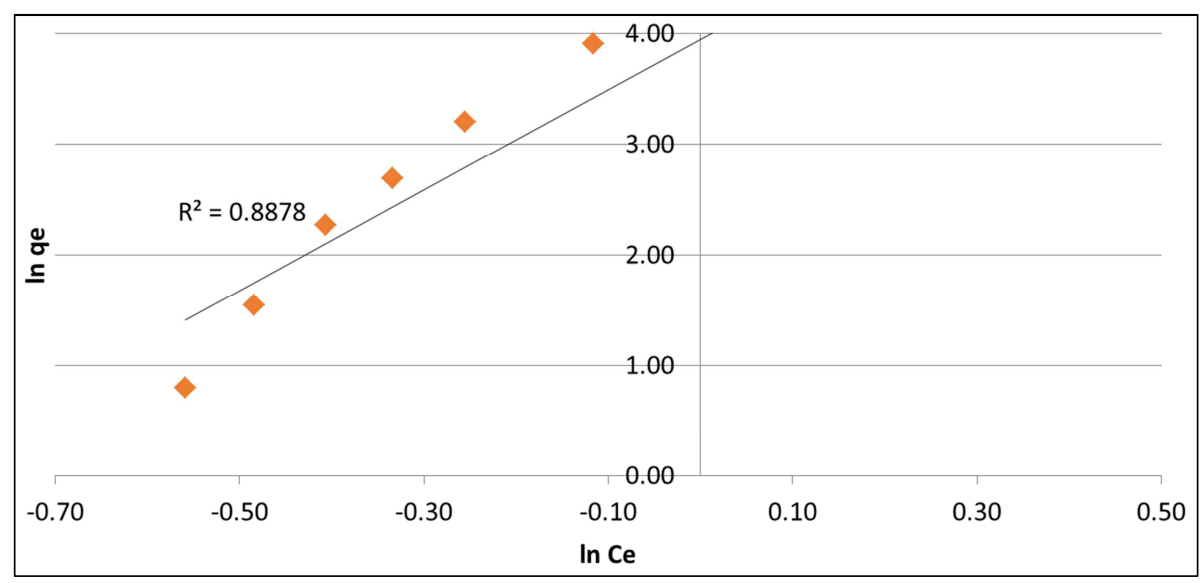

Figure 6. Freundlich adsorption isotherm for removal of the As (III) for when both 0.1g nano iron oxide and BACI-2017 with mesh size (4x8) are used.

And finally, the maximum As (III) removal capacity calculated by Freundlich adsorption isotherm is found to be $455 \mathrm{mg} / \mathrm{g}$ [Table 11 and Figure 7] for the tests where 0.1g BACI-2017 with mesh sizes of 100 or higher are used.

Table 11. Results to determine Freundlich isotherm for when both BACI-2017 with 100 mesh or higher and $0.1 \mathrm{~g}$

\begin{tabular}{lllll}
\hline No. & qe $(\mathbf{m g} / \mathbf{g})$ & Ce $(\mathbf{m g} / \mathbf{L})$ & Lnqe & LnCe \\
\hline 1 & 49.5 & 1 & 3.90 & 0 \\
2 & 98.00 & 4 & 4.58 & 1.39 \\
3 & 145.50 & 9 & 4.98 & 220 \\
4 & 190.00 & 20 & 5.25 & 3.00 \\
5 & 230.00 & 40 & 5.44 & 3.69 \\
6 & 455.00 & 90 & 6.12 & 4.50 \\
\hline
\end{tabular}

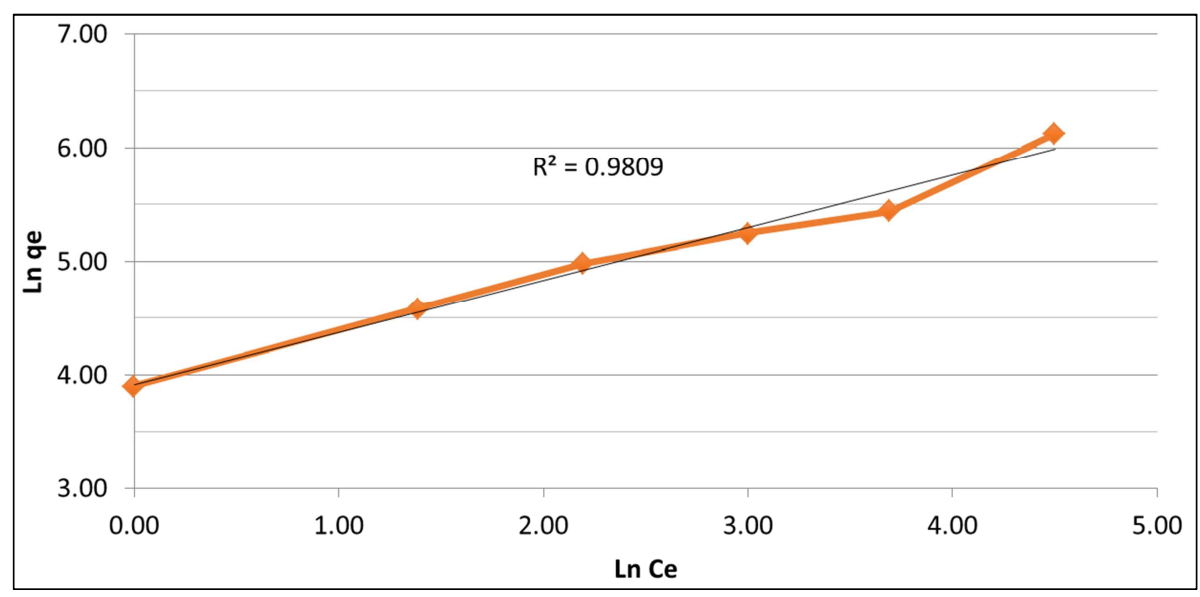

Figure 7. Freundlich adsorption isotherm for removal of As (III) in presence of BACI-2017 with 100 mesh or higher and 0.1g

\section{Conclusion}

In this study the adsorption capacity of removing As (III) from contaminated water with BACI-2017 with mesh size (4x8) and mesh size of 100 or higher was compared where nano particles of iron oxide were also present. The maximum capacity of As (III) removal in presence of nano iron oxide was found to be $19.47 \mathrm{mg} / \mathrm{g}$ whereas for combined nano iron oxide and BACI-2017 was significantly raised to $99.36 \mathrm{mg} / \mathrm{g}$. The experimental data were analyzed using Langmuir and Freundlich models. The adsorption data are best predicted by Freundlich model. The results show, as expected, with decreasing the article size of BACI- 2017 the adsorption capacity was dramatically increased. Most importantly, it is demonstrated that the presence of BACI-2017 adsorber is advantageous in removal of As (III) from contaminated water in a short period of time as short as 15 minutes.

\section{References}

[1] Sharf Ilahi Siddiqui, Iron oxide and its modified forms as an adsorbent for arsenic removal: A comprehensive recent advancement, October 2017Volume 111, Pages 592-626 Journal of Biomechanics, DOI: http://dx.doi.org/10.1016/j.psep.2017.08.009.

[2] N. Akartasse et. al. Natural product based composite for extraction of arsenic (III) from waste water, Chemistry Central Journal (2017) 11:33 DOI 10.1186/s13065-017-0261-9. 
[3] Bringas E, Saiz J, Ortiz, Removal of As (V) from groundwater using functionalized magnetic adsorbent materials: efects of competing ions. Sep Purif Technol 156:699-707 (2015).

[4] Qasim, Syed R, Water Engineering (Planning, Design, Utilization), Volume I and II, Third edition, Hafiz publishing, 2013, pp. 9-32 (Vol. 1), Pages 335-334 (Vol. II).

[5] Christine Marie Georae, Laura Sima. M Helena Jahuira Arias, Jana Mihalic, Lilia Z Cabrera, David Danz, William Checkley \& Robert H Gilman." Arsenic exposure in drinking Water: an recognized health threat in peru" Accepted: 22 January 2014.

[6] [Nina Ricci Nicomel, Karen Leus, Karel Folens, pascal VanDer Veort and Gijs Du Laing. "Technologies for Arsenic Removal from water: current status and future perspectives" Accepted: 17 December 2015.
[7] H. Ghafourian, M. Rabbani, Z. Ghazanfari, Novel Carbon Porous Material with Nanostructural for Separation of arsenic (III) from Water with Highest Adsorption Capacity International Journal of Environmental Chemistry Volume 2, Issue 2, March 2017, Pages: 27-30 779May 24, 2017.

[8] Esmaeli, Akbar, Naghizadeh, Sedigheh 'Biological absorption of lead in milk by an orange peel absorbent with alkaline correction, Journal of Food Science and Technology" Feb. 20, 2011, pp. 81 and 82.

[9] Farzinius, W. Water Analysis, Towayipour, Ahmad, Second Edition, Arak University, Summer 2013, pp. 154-148.

[10] Tavakoli Mohammadi, Mohammad Reza, Pertani, Sadegh, Marzban, Mehdi, Sources of heavy metal contamination in Zanjan province using GIS, Proceedings of the Siamese Geosciences Conference, 1st to 3rd March 2011. 